\title{
Association study between functional polymorphisms in the TNF-alpha gene and obsessive-compulsive disorder
}

\author{
Estudo de associação entre polimorfismos funcionais do gene do TNF-alfa \\ e transtorno obsessivo-compulsivo \\ Carolina Cappi', Renan Kawano Muniz', Aline Santos Sampaio', Quirino Cordeiro², Helena Brentani', \\ Selma A. Palácios ${ }^{3}$, Andrea H. Marques', Homero Vallada', Euripedes Constantino Miguel', Luiza \\ Guilherme ${ }^{3}$, Ana Gabriela Hounie ${ }^{1}$
}

\begin{abstract}
Obsessive-compulsive disorder (OCD) is a prevalent psychiatric disorder of unknown etiology. However, there is some evidence that the immune system may play an important role in its pathogenesis. In the present study, two polymorphisms (rs1800795 and rs361525) in the promoter region of the cytokine tumor necrosis factor-alpha (TNFA) gene were genotyped in 183 OCD patients and in 249 healthy controls. The statistical tests were performed using the PLINK ${ }^{\circledR}$ software. We found that the A allele of the TNFA rs361525 polymorphism was significantly associated with OCD subjects, according to the allelic $\chi^{2}$ association test $(p=0.007)$. The presence of genetic markers, such as inflammatory cytokines genes linked to OCD, may represent additional evidence supporting the role of the immune system in its pathogenesis.
\end{abstract}

Key words: cytokines, genetic markers, mental disorder, polymorphism.

\section{RESUMO}

O transtorno obsessivo-compulsivo (TOC) é um quadro psiquiátrico de prevalência considerável na população e de etiologia desconhecida. No entanto, há evidências de que o sistema imunológico pode desempenhar um papel importante em sua patogênese. No presente estudo, dois polimorfismos (rs1800795 e rs361525), localizados na região promotora do gene que codifica a citocina conhecida como fator de necrose tumoral alfa (TNFA), foram genotipados em 183 pacientes com TOC e 249 controles saudáveis. Os testes estatísticos foram realizados utilizando-se o software PLINK ${ }^{\circledR}$. Assim, evidenciou-se que o alelo A do polimorfismo rs361525 apresentava associação estatisticamente significante com o TOC ( $p=0,007)$. A presença de marcadores genéticos, tais como genes que codificam citocinas inflamatórias, associados com TOC, confere suporte adicional ao papel do sistema imunológico na patogênese desse transtorno.

Palavras-Chave: citocinas, marcadores genéticos, transtorno mental, polimorfismo.

The obsessive-compulsive disorder (OCD) is characterized by recurrent unwanted thoughts (obsessions), usually accompanied by repetitive behaviors (compulsions) intended to alleviate the anxiety caused by obsessions. OCD is a relatively common disorder, with a lifetime prevalence of 2 to $3 \%^{1}$.

There is solid evidence for the involvement of genetic factors in the etiology of OCD. Although once thought to be primarily psychological in origin, there is now compelling evidence from twin and family studies that OCD has a genetic background. However, the identification of environmental and genetic susceptibility factors remains an open field for research.
The immune system is one of the interfaces between the environment and the central nervous system (CNS), justifying the researches on cytokines and their genetic determinants ${ }^{2}$.

The role of the immune system in CNS processes has long been under investigation in the pathogenesis of a variety of neuropsychiatric disorders, such as depression, dementia, and schizophrenia ${ }^{3}$. Several immune parameters have also been investigated in some anxiety disorders, such as post-traumatic stress disorder, panic disorder, social phobia, and $\mathrm{OCD}^{4}$. Recent reports have suggested that pro-inflammatory cytokines, like the tumor necrosis factor-alpha (TNFA), are involved in OCD pathophysiology ${ }^{5}$.

${ }^{1}$ Department and Institute of Psychiatry, Medical School of University of São Paulo, São Paulo SP, Brazil;

${ }^{2}$ Department of Psychiatry and Psychological Medicine, Santa Casa Medical School, São Paulo SP, Brazil;

${ }^{3}$ Heart Institute (InCor), University of São Paulo Medical School, São Paulo SP, Brazil.

Correspondence: Quirino Cordeiro; Centro de Atenção Integrada à Saúde Mental da Irmandade da Santa Casa de Misericórdia de São Paulo; Rua Major Maragliano 241 / $4^{\circ}$ andar; 04017-030 São Paulo SP - Brasil; E-mail: qcordeiro@yahoo.com

Support: CAPES/PRODOC, FAPESP (grants 98/15-013-9 and 2005/55628-8), and CNPq.

Conflict of interest: There is no conflict of interest to declare.

Received 19 October 2011; Received in final form 31 October 2011; Accepted 07 November 2011 
Although cytokines are large soluble peptides, studies have identified several mechanisms by which cytokines enter and stimulate the brain. They act directly on the CNS by crossing certain regions at the blood-brain barrier, both passively (circumventricular organs, subfornical organ and area postrema) and via active transportation. In addition, cytokines can act indirectly by signaling the brain via stimulation of visceral (vagal) afferents, which are projected to the tractus solitarius nucleus in the brainstem. Finally, cytokines can also act on endothelial cells of brain vasculature or glia cells in the circumventricular organs inducing synthesis and release of secondary messengers, such as central cytokines, prostaglandins, and nitric oxide ${ }^{6}$. Furthermore, some studies have shown that there is also release of pro-inflammatory cytokines (IL-1, IL-6, and TNFA) by neurons and glia cells inside the CNS 7 .

In recent years, the discovery of multiple functions of cytokines in the CNS suggests that they play a central role in complex CNS functions such as cognition and memory. In addition, cytokines may act as immune stressors, causing neurochemical changes and activating other pathways that can influence intracellular, apoptotic and oxidative mechanisms, which might contribute to mood and anxiety-related disorders 5 .

TNFA is a cytokine that has been investigated in neuropsychiatric disorders, due to its effects on the CNS. It is produced by macrophages and circulating monocytes and glia cells, playing an important role in a variety of infectious, inflammatory, and autoimmune conditions as well as in synaptic plasticity. Studies have demonstrated that cytokine production during the inflammatory process can lead the brain to develop neurochemical, neuroendocrine, neuroimmune, and behavioral changes ${ }^{9}$. Taking all these data into account, polymorphisms in genes that codify for cytokines, especially TNFA, are potential candidates to explain the OCD pathophysiology.

Although several reports have focused on the role of cytokines in OCD, this is still not completely elucidated. Cytokine studies in OCD patients have shown contradictory results, from increase in type-I cytokines in cerebrospinal fluid and in their plasma levels to either decrease of natural killer (NK) activity and pro-inflammatory cytokines levels or lack of alterations ${ }^{5}$.

TNFA gene polymorphisms have been studied in several neuropsychiatric disorders, such as Alzheimer's disease, schizophrenia, and depression. However, there are few studies investigating the relationship between polymorphisms in cytokine genes and OCD patients. A previous case-control study from the authors of this article found a significant association between the TNFA -308 and -238 G/A polymorphisms and $\mathrm{OCD}^{10}$. We have also investigated a polymorphism in the nuclear factor of kappa light polypeptide gene enhancer in B-cells inhibitor-like 1 - NFKBIL1 (rs2071592) - in another case-control study, finding no association between that polymorphism and $\mathrm{OCD}^{11}$.
Thus, in the present paper we investigated polymorphisms in the gene that codifies for the cytokine TNFA, using a case-control approach in a larger sample than the one used in the former paper from our group, hoping to validate the present findings.

\section{METHODS}

\section{Sample}

All patients from our dataset who met DSM-IV criteria for OCD were included in the study. Miguel et al. made a detailed description of the ascertainment ${ }^{12}$. Briefly, OCD patients were recruited through the Obsessive-Compulsive Spectrum Disorders Program (PROTOC at University of São Paulo). The final sample consisted of 183 OCD patients and 249 healthy controls. In the present study, 111 subjects from the previous investigation were included in the analysis ${ }^{10}$. Informed consents approved by the local ethical committee were signed by all participants. The project was approved by the Institutional Review Board of University of São Paulo.

\section{Genotyping}

Venous blood samples were collected in anticoagulant (EDTA) $5 \mathrm{~mL}$ tubes. Genomic DNA was extracted according to standard protocols. The genotyping of the TNFA -308 (rs1800629) and -238 G/A (rs361525) polymorphisms was performed using a PCR- restriction fragment length polymorphism assay, as described by Ramasawmy et al. ${ }^{13}$.

\section{Statistical analysis}

Deviation from Hardy-Weinberg equilibrium (HWE) was tested separately in healthy controls and patients by using the PLINK ${ }^{\circledR}$ software $^{14}$. The association test was also performed using PLINK ${ }^{\circledR}$. To reduce the odds of false-positive findings, permutation analysis with 100,000 permutations was performed.

\section{RESULTS}

Allele frequencies and genotypic distribution of the polymorphisms were in the HWE (patients: $\mathrm{p}=0.7385$; controls: $\mathrm{p}=0.14$ ) regarding the rs 1800629 in both groups, as well as the rs361525 in the Control Group ( $\mathrm{p}=0.22$ ). The rs361525 marker in the Case Group was out of the HWE ( $\mathrm{p}=0.0004)$.

The A allele (adenine, the minor allele) of the TNFA rs361525, which has a frequency of 0.054 , was significantly associated with OCD subjects according to the allelic $\chi^{2}$ association test ( $\mathrm{p}=0.007$ ), as can be seen in Table. The major allele in this single nucleotide polymorphism (SNP) is a guanine (G). The results remained significant after the 100,000 permutation analysis $(\mathrm{p}=0.004)$. 
Table. Allelic $\chi^{2}$ association test for TNFA single markers in OCD subjects.

\begin{tabular}{lccccccc} 
SNP & Position & Minor Allele & FA & FU & $\chi^{2}$ & P & OR \\
\hline s1800629 & 31651010 & A & 0.123 & 0.09 & 2.094 & 0.1479 & 1.377 \\
rs361525 & 31651080 & A & 0.085 & 0.03 & 11.33 & $0.007^{*}$ & 2.788 \\
\hline
\end{tabular}

TNFA:tumor necrosis factor-alpha; OCD: obsessive-compulsive disorder; SNP: single nucleotide polymorphism; FA: frequency of minor allele in cases; FU: frequency of minor allele in controls; $p$-value: asymptotic p-value for this test; OR: estimated odds ratio (for minor allele, i.e. major allele is reference); *:significant results.

\section{DISCUSSION}

In this study we investigated if there were associations between two markers on the TNFA gene with OCD subjects, using the allelic $\chi^{2}$ association test. We found a significant association between the A allele of the TNFA rs361525 and OCD subjects, which persisted after 100,000 permutations (permuted $\mathrm{p}=0.03$ ). This result is a replication of the findings by Hounie et al. ${ }^{10}$ in an expanded sample, supporting an association between TNFA and OCD.

It has been suggested that the polymorphisms investigated in the present paper affect TNFA transcription. Studies with both positive $\mathrm{e}^{15,16}$ and negative $\mathrm{e}^{17-19}$ findings investigating TNFA polymorphisms and their transcription have been published ${ }^{20-24}$. However, it has been reported that TNFA plasma levels vary with age, body mass index, gender, time of the day, medicine intake, and several other factors ${ }^{5}$. Additionally, changes in behavior may probably be related to the ones in the CNS through local production of cytokines and not through plasma levels ${ }^{25}$. Consequently, it is not surprising that studies investigating the relationship between OCD and cytokine plasma levels have inconsistent results, and the polymorphisms found in this study to be associated with OCD may not be sufficient to explain TNFA plasma levels, which are the results of a complex chain of interconnected genetic and environmental factors.

It is still unclear how cytokines mediate OCD or other psychiatric/neurological symptoms. In an animal model of cytokine-mediated cognitive functions, such as memory and learning, it has been demonstrated that the presence of TNFA under immunologically non-challenged conditions is essential for the normal functioning of memory and learning. The literature demonstrates that cytokines can profoundly affect the metabolism of serotonin, norepinephrine, and dopamine ${ }^{26}$. It appears to be of significance the ability of the immune system to activate the indolamine-2,3-dehydrogenase enzyme. It breaks down tryptophan and can influence serotoninergic neurotransmission ${ }^{27}$. Besides, serotonin reuptake inhibitors and a polymorphism in the serotonin transporter gene that affects monoamine metabolism have been shown to influence the development of cytokine-induced depressive-like behavior in laboratory animals and in humans ${ }^{28}$.

The potential clinical application of the association between inflammation and depression is that inflammatory biomarkers may identify depressed patients, who are less likely to respond to conventional antidepressant treatment and might provide an indicator of treatment response $\mathrm{e}^{29,30}$.
The present investigation has some limitations. The small sample size can raise the odds of false-negative results. However, this study replicated in a larger sample the results from a previous study ${ }^{10}$. It is also somewhat concerning that the Case Group was not in HWE for the rs361525. On the other hand, deviations from the HWE can be very informative. In control subjects, deviations could indicate that one or more of the model assumptions have been violated or that a genotyping error has occurred. In case subjects, deviation from HWE, assuming that sources of error have been eliminated, may indicate the association of a locus with disease. As the HWE deviation was exclusive to the affected sample, herein, this could be explained by a "selection of risk alleles" in the Case Group.

Investigations conducted in highly admixed ethnicity populations, such as the Brazilian, may bring problems regarding ethnical stratification ${ }^{11}$. In conclusion, the results of the present investigation provide evidence for the association between the TNFA polymorphism and OCD in the Brazilian sample. Furthermore, it is always possible that these polymorphisms are in linkage disequilibrium with non-identified genes, which are in fact those contributing to the pathogenesis of OCD or even with other polymorphisms within the TNFA. Our results suggest that the evaluation of this gene is important to clarify its role in the OCD development. More comprehensive polymorphism coverage within the TNFA using high-throughput sequence of the entire gene is warranted. However, to confirm the association of the TNFA polymorphism with OCD, further studies must be conducted focusing on ethnical aspects. Moreover, differences in association of the TNFA polymorphism and OCD, found in different investigations, could be clarified by the analysis of larger case-control studies, additional family-based studies, and especially linkage disequilibrium mapping of TNFA, which should be considered a high-priority gene given its potentially important influence on the risk for OCD.

\section{ACKNOWLEDGMENTS}

We thank Juliana B. Diniz, Ivanil Moraes, Marines Joaquim, Sonia Borcato, Ana Carolina Ferreira Rosa, and Maria Conceição do Rosário for their assistance in many steps of this study, including patient and relatives' interviews, blood collection, and other functions. 


\section{References}

1. Weissman MM, Bland RC, Canino GJ, et al. The cross national epidemiology of obsessive compulsive disorder. The Cross National Collaborative Group. J Clin Psychiatry 1994;55:5-10.

2. Hettema JM, Neale MC, Kendler KS. A review and meta-analysis of the genetic epidemiology of anxiety disorders. Am J Psychiatry 2001;158:1568-1578.

3. García-Bueno B, Caso JR, Leza JC. Stress as a neuroinflammatory condition in brain: damaging and protective mechanisms. Neurosci Biobehav Rev 2008;32:1136-1151.

4. Maes M, Lin AH, Delmeire L, et al. Elevated serum interleukin-6 (IL-6) and $\mathrm{IL}-6$ receptor concentrations in posttraumatic stress disorder following accidental man-made traumatic events. Biol Psychiatry 199;45:833-839.

5. Konuk N, Tekin IO, Ozturk U, et al. Plasma levels of tumor necrosis factor-alpha and interleukin-6 in obsessive compulsive disorder. Mediators Inflamm 2007;2007:1-5.

6. Silverman MN, Pearce BD, Biron CA, Miller AH. Immune modulation of the hypothalamic-pituitary-adrenal (HPA) axis during viral infection. Viral Immunol 2005;18:41-78.

7. Szelényi J, Vizi ES. The catecholamine cytokine balance: interaction between the brain and the immune system. Ann N Y Acad Sci 2007;1113:311-324.

8. Vassalli P. The pathophysiology of tumor necrosis factors. Ann Rev Immunol 1992;10:411-452.

9. Licinio J, Wong ML. The role of inflammatory mediators in the biology of major depression: central nervous system cytokines modulate the biological substrate of depressive symptoms, regulate stress-responsive systems, and contribute to neurotoxicity and neuroprotection. Mol Psychiatry 1999;4:317-327.

10. Hounie AG, Cappi C, Cordeiro Q, et al. TNF-alpha polymorphisms are associated with obsessive-compulsive disorder. Neurosci Lett 2008;442:86-90

11. Cordeiro Q, Cappi C, Sampaio AS, et al. Association study between the -62A/T NFKBIL1 polymorphism and obsessive-compulsive disorder. Rev Bras Psiquiatr 2009;31:131-135.

12. Miguel EC, Ferrão YA, Rosário MCD, et al. The Brazilian Research Consortium on Obsessive-Compulsive Spectrum Disorders: recruitment, assessment instruments, methods for the development of multicenter collaborative studies and preliminary results. Rev Bras Psiquiatr 2008;30:185-196.

13. Ramasawmy R, Faé KC, Spina G, et al. Association of polymorphisms within the promoter region of the tumor necrosis factor-alpha with clinical outcomes of rheumatic fever. Mol Immunol 2007;44:1873-1878.

14. Purcell S, Neale B, Todd-Brown K, et al. PLINK: a tool set for wholegenome association and population-based linkage analyses. Am J Hum Genet 2007;81:559-575.

15. Abraham LJ, Kroeger KM. Impact of the -308 TNF promoter polymorphism on the transcriptional regulation of the TNF gene: relevance to disease. J Leukoc Biol 1999;66:562-566.

16. Sallakci N, Akcurin G, Köksoy S. TNF-alpha G-308A polymorphism is associated with rheumatic fever and correlates with increased TNFalpha production. J Autoimmun 2005;25:150-154.

17. Brinkman BM, Zuijdeest D, Kaijzel EL, Breedveld FC, Verweij CL. Relevance of the tumor necrosis factor alpha (TNF alpha) -308 promoter polymorphism in TNF alpha gene regulation. J Inflamm 1995;46:32-41.

18. Westendorp RG, Langermans JA, Huizinga TW, Verweij CL, Sturk A Genetic influence on cytokine production in meningococcal disease. Lancet 1997;349:1912-1913.

19. Uglialoro AM, Turbay D, Pesavento PA, et al. Identification of three new single nucleotide polymorphisms in the human tumor necrosis factor-alpha gene promoter. Tissue Antigens 1998;52:359-367.

20. Drouet C, Shakhov AN, Jongeneel CV. Enhancers and transcription factors controlling the inducibility of the tumor necrosis factor-alpha promoter in primary macrophages. J Immunol 1991;147:1694-1700.

21. Fong $\mathrm{CL}$, Siddiqui $\mathrm{AH}$, Mark DF. Identification and characterization of a novel repressor site in the human tumor necrosis factor alpha gene. Nucleic Acids Res 1994;22:1108-1114.

22. Pociot F, D’Alfonso S, Compasso S, Scorza R, Richiardi PM. Functional analysis of a new polymorphism in the human TNF alpha gene promoter. Scand J Immunol 1995;42:501-504.

23. Kaluza W, Reuss E, Grossmann S, et al. Different transcriptional activity and in vitro TNF-alpha production in psoriasis patients carrying the TNF-alpha 238A promoter polymorphism. J Invest Dermatol 2000;114:1180-1183.

24. Bayley JP, de Rooij H, van den Elsen PJ, Huizinga TW, Verweij CL. Functional analysis of linker-scan mutants spanning the $-376,-308$, -244 , and -238 polymorphic sites of the TNF-alpha promoter. Cytokine 2001;14:316-323.

25. Sawada M, Imamura K, Nagatsu T. Role of cytokines in inflammatory process in Parkinson's disease. J Neural Transm 2006;70:373-381.

26. McEwen BS. Physiology and neurobiology of stress and adaptation: central role of the brain. Physiol Rev 2007;87:873-904.

27. Kohl C, Sperner-Unterweger B. IDO and clinical conditions associated with depressive symptoms. Curr Drug Metab 2007;8:283-287.

28. Mössner R, Mikova O, Koutsilieri E, et al. Consensus paper of the WFSBP Task Force on Biological Markers: biological markers in depression. World J Biol Psychiatry 2007;8:141-174.

29. JunT,Pae C, ChaeJ, et al. Possible association between-G308A tumour necrosis factor-alpha gene polymorphism and major depressive disorder in the Korean population. Psychiatr Genet 2003;13:179-181.

30. Miller AH. Norman Cousins Lecture. Mechanisms of cytokine-induced behavioral changes: psychoneuroimmunology at the translational interface. Brain Behav Immun 2009;23:149-158. 